\title{
PENGARUH KUALITAS PELAYANAN DAN KEPUASAN KONSUMEN TERHADAP LOYALITAS PELANGGAN PADA PT SUMBER ALFARIA TRIJAYA TBK
}

\author{
Riki Supiyani ${ }^{1}$, Sri Afridola ${ }^{2}$ \\ ${ }^{1}$ MahasiswaProgram Studi Manajemen, Universitas Putera Batam \\ ${ }^{2}$ Dosen Program Studi Manajemen, Universitas Putera Batam \\ E-mail:rikisupiyani97@gmail.com
}

\begin{abstract}
The development of the retail business, at the same time as a rapid development should no longer be managed traditionally, but in a modern way so that it becomes an innovative, dynamic, and competitive business. One of the advantages in running a retail business is that it has a broad market reach, not only opening retail in big cities, but also extending to the edge of the city. PT Sumber Alfaria Trijaya Tbk is better known as Alfamart which was established in 1989 by Djoko Susanto. Competition in the world of commerce is felt and changes in the environment and technology are increasingly rapid and continue to support competition today, customer-oriented marketing strategies, making retail companies must understand well the behavior and needs of their customers to achieve maximum benefits for Alfamart, Alfamart is a retail provide various daily needs for consumption by the community. Alfamartm provides staple goods at affordable prices, convenient shopping, and locations that are easily accessible. This study aims to identify the effect of service quality and customer satisfaction on customer loyalty to PT Sumber Alfaria Trijaya Tbk. The sampling technique used to collect data in this study was random sampling determined in accordance with the coverage area of each service unit by distributing questionnaires to customers. With a total questionnaire of 382 customers from PT Sumber Alfaria Trijaya Tbk. Data were analyzed using Structural Equation Model (SEM). The results of this study stated that service quality has a positive and significant influence on customer loyalty. Consumer satisfaction has a positive and significant effect on customer loyalty.
\end{abstract}

Keywords: Service Quality; Consumer Satisfaction; Loyalty Customer

\section{PENDAHULUAN}

Perkembangan bisnis ritel, pada saat yang sedemikan pesat seharusnya tidak lagi dikelola secara tradisional, melainkan dengan cara modern sehingga menjadi bisnis yang inovatif, dinamis, dan kompetitif. Salah satu keuntungan dalam 
menjalankan bisnis ritel yaitu mempunyai jangkauan pasar yang luas, tidak hanya membuka ritel di kota besar, namun juga bisa meluas sampai kepinggiran kota. PT Sumber Alfaria Trijaya Tbk ini lebih di kenal dengan sebutan Alfamart yang berdiri sejak tahun 1989 oleh Djoko Susanto. Persaingan yang semakin ketatnya antar ritel sehingga harus meningkatkan kualitas pelayanan di setiap ritel sehingga pelanggan akan merasa nyaman dalam berbelanja. Alfamart harus meningkatkan kualitas pelayanan dari hal yang kecil mulai dari menyapa dan melayani konsumen yang datang mengunjungi ritel, selain itu kebersihan dan tata letak barang yang sesuai dengan jenis-jenis produknya juga menjadi nilai kualitas pelayanan bagi pelanggan. Kualitas pelayanan yang tidak baik seperti karyawannya cuek ketika datang pelanggan tidak disapa dan senyum pun tidak, kebersihan dan tata letak jenis barang yang tidak beraturan pelanggan akan enggan untuk berbelanja di ritel tersebut dan mencari ritel lain. Alfamart adalah ritel yang menyediakan berbagai kebutuhan sehari-hari untuk di konsumsi oleh masyarakat. Alfamart menyediakan barang-barang kebutuhan pokok dengan harga yang terjangkau, tempat belanja yang nyaman, serta lokasi yang mudah dijangkau. Sehingga konsumen tidak perlu jauh-jauh untuk berbelanja kebutuhan sehari-hari seperti masyarakat yang ada di sekitar Jalan Harapan River, Sekupang, Kota Batam, bisa langsung datang ke
Alfamart Pratiwi. dikarenakan kualitas pelayanan yang tidak baik terjadinya penurunan dan penaikan penjualan di karenakan pelanggan yang datang ke alfamart pondok pratiwi tidak dilayani dengan baik dalam hal pelanggan bertanya produk yang dicari dan pelanggan yang membeli galon dibiarkan anggkat galonnya ke motor sendiri tanpak di antarkan galonnya oleh karyawan alfamart, dan konsumen merasa tidak puas dengan harga yang ada dirak tidak sesuai dengan di sistem/kasir pada saat membayar, dan pelanggan tidak loyal karena karyawan cuek terhadap pelanggan sehingga menyebabkan konsumen tidak loyal terhadap alfamart pondok pertiwi.

Adapun tujuan penelitian sebagai berikut:

1. Untuk mengetahui kualitas pelayanan

berpengaruh terhadap loyalitas pelanggan di Alfamart Pondok Pratiwi.

2. Untuk mengetahui kepuasan konsumen berpengaruh terhadap loyalitas pelanggan di Alfamart Pondok Pratiwi.

3. Untuk mengetahui kualitas pelayanan dan kepuasan konsumen berpengaruh terhadap loyalitas pelanggan Alfamart Pondok Pratiwi.

\section{KAJIAN TEORI}

\subsection{Kualitas Pelayanan}

(Tjiptono, 2012:51), "Kualitas merupakan suatu kondisi dinamis yang berhubungan dengan produk, jasa, manusia, proses, dan lingkungan yang memenuhi atau melebihi 
harapan". Menurut Lupiyoadi (2014:63) bahwa: Kualitas adalah perpaduan antara sifat dan karakteristik yang menentukan sejauh mana keluaran dapat memenuhi persyaratan kebutuhan pelanggan, jadi pelanggan yang menentukan dan menilai sampai seberapa jauh sifat dan karakteristik tersebut memenuhi kebutuhannya.

Adapun indikator-indikator kualitas pelayanan (Putri \& Kartika, 2017:45) sebagai berikut:

1. Tangibles, atau bukti fisik

2. Reliability, atau kehandalan

3. Responsiveness, atau ketanggapan

4. Assurance, atau jaminan

\subsection{Kepuasan Konsumen}

(Daryanto, 2014:43) mengatakan kepuasan konsumen adalah suatu penilaian emosional dari konsumen setelah konsumen menggunakan produk dimana harapan dan kebutuhan konsumen yang menggunakannya terpenuhi. Menurut (Kotler, 2016:54) Kepuasan konsumen adalah tingkat perasaan konsumen akan kesenangan atau kekecewaan yang dihasilkan dari membandingkan kinerja produk yang dirasakan (atau hasil) dengan harapan mereka.Adapun indikator-indikator kepuasan konsumen (Sangaji, 2013:181):

1. Kesesuaian harapan

2. Minat berkunjung kembali

3. Kesediaan merekomendasikan

\subsection{Loyalitas Pelanggan}

Menurut (Sangaji, 2013:104) menjelaskan bahwa kesetiaan adalah komitmen konsumen untuk mengatur ulang atau membeli kembali produk atau layanan di masa depan, meskipun dampak kondisi dan upaya pemasaran dapat menyebabkan perubahan perilaku.

(Tjiptono, 2012:56) menyatakan bahwa selama ini loyalitas pelanggan kerap kali dikaitkan dengan perilaku pembelian ulang. Keduanya memang berhungan, namun sesungguhnya berbeda. Dalam konteks merek, misalnya loyalitas mencerminkan komitmen psikologis terhadap merek tertentu, sedangkan perilaku pembelian ulang semata-mata menyangkut pembelian merek tertentu yang sama secara berulangkali (bisa dikarenakan memang karena satu-satunya merek yang tersedia, merek yang termurah dan sebagainya). Pada dasarnya Loyalitas yang sesungguhnya tidak akan dapat terbentuk apabila pelanggan tidak atau belum melakukan proses pembelian terlebih dahulu. Pelanggan yang puas akan memiliki tingkat loyalitas yang tinggi terhadap produk atau jasa yang ditawarkan dibandingkan dengan pelanggan yang tidak puas. Loyalitas pelanggan merupakan kelanjutan dari kepuasan pelanggan, walaupun sebenarnya loyalitas tidak mutlak tercipta dari hasil kepuasan pelanggan. Adapun Indikatorindikator loyalitas pelanggan sebagai berikut:

1. Melakukan pembelian berulang secara teratur. 
2. Membeli antar lini produk dan jasa.

3. Mereferensikan kepada orang lain.

\subsection{Peneliti Terdahulu}

Penelitian terdahulu bertujuan mengetahui hasil penelitian yang telah dilakukan sebagai gambaran untuk penelitian selanjutnya yang sama. Berikut adalah kajian penelitian terdahulu yang berkaitan dengan penelitian ini. Berdasarkan hasil penelitian oleh Leni Astuti dan Ir, Irmawati tahun 2015 yang berjudul pengaruh kualitas pelayanan dan kepuasan konsumen terhadap loyalitas pelanggan Studi Pada Bank Jateng Syariah Universitas Muhammadiyah Surakarta.

Berdasarkan penelitian terdahulu dengan penelitian yang dilakukan memiliki variabel yang sama dan perbedaannya adalah objek penelitian.

\subsection{Kerang Pemikiran Gambar 1}

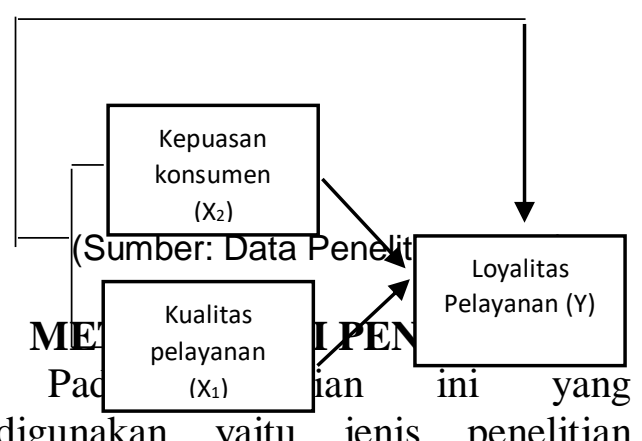

kuantitatif. Pada penelitian kuantitatif ini digunakan dua jenis variabel, yakni variabel independen (bebas) meliputi Kualitas Pelayanan $\left(\mathrm{X}_{1}\right)$ dan Kepuasan Konsumen $\left(\mathrm{X}_{2}\right)$ dan variabel dependen (terikat) meliputi Loyalitas Pelanggan (Y). Penelitian ini bertujuan untuk mengetahui pengaruh antara kedua variabel independen terhadap variabel dependen. Pada penelitian ini peneliti menggunakan jenis penelitian survei. Kuswanto, (2012: 66). Definisi operasional adalah suatu definisi yang diberikan kepada suatu variabel atau konstrak dengan cara memberikan arti, atau mespesifikasikan kegiatan ataupun memberikan suatu operasional yang diperlukan untuk mengukur konstrak atau variabel tersebut. Menurut (Sugiyono, 2012: 38). Variabel penelitian adalah suatu atribut atau sifat atau nilai dari orang, obyek atau kegiatan yang mempunyai variasi tertentu yang ditetapkan oleh peneliti untuk dipelajari dan kemudian ditarik kesimpulannya.

Populasi dalam penelitian ini adalah seluruh pelanggan yang pernah membeli produk di PT Sumber Alfaria Trijaya Tbk pada rentang waktu bulan Maret sampai Oktober sebanyak 57.388.

Sampel merupakan bagian dari jumlah dan karakteristik yang dimiliki oleh populasi tersebut. Bila populasi besar, dan peneliti tidak mungkin mempelajari semua yang ada pada populasi, maka peneliti dapat menggunakan sampel yang diambil dari populasi itu (Sugiyono, 2012:81). Responden dipilih secara 
acak yang ditentukan sesuai dengan cakupan wilayah masing-masing unit pelayanan. Sedangkan untuk besaran sampel dan populasi dapat menggunakan tabel sampel dari Krejcie dan Morgan.

Sugiyono, (2012: 225). Teknik pengumpulan data merupakan langkah yang paling strategis dalam penelitian, karena tujuan utama dari penelitian adalah mendapatkan data. Bila dilihat dari sumber datanya, maka pengumpulan data dapat menggunakan sumber primer dan sumber sekunder. Dalam penelitian ini peneliti menggunakan data primer. Peneliti data yang digunakan adalah sebagai berikut:

1. Data Primer

(Sugiyono, 2012: 137). Data Primer adalah sumber data yang langsung memberikan data kepada pengumpul data. Data primer diperoleh dengan menyebarkan kuesioner kepada respondennya, yaitu pelanggan Alfamart Pondok Pratiwi.

2. Data Sekunder

(Sugiyono, 2012:137). Data Sekunder adalah sumber yang tidak langsung memberikan data kepada pengumpul data. Peneliti menggunakan studi pustaka untuk memperoleh data sekunder.

Untuk mempermudah pengujian validitas dan reliabilitas butir-butir pertanyaan penelitian, pembentukan garis regresi beserta pengujian hipotesis penelitian menggunakan alat bantu SPSS versi 25 .
(Sugiyono, 2012:267). Validitas merupakan derajat ketepatan antara data yang terjadi pada obyek penelitian dengan data yang dapat dilaporkan oleh peneliti. Dengan demikian data yang valid adalah data yang tidak berbeda antar data yang dilaporkan oleh peneliti dengan data yang sesungguhnya terjadi pada obyek penelitian. Dalam menentukan kelayakan dan tidaknya suatu item yang akan digunakan uji signifikan koefisien korelasi pada taraf 0,05 artinya suatu item dianggap memiliki tingkat keberterimaan atau valid jika memiliki korelasi signifikan terhadap skor total item. Berikut tabel yang menggambarkan range validitas.

(Sujarweni, 2014:85) Reliabilitas menunjuk padapengertian bahwa instrumen yang digunakan dapat mengukur sesuatu yang diukur secara konsisten dari waktu ke waktu. Uji reliabilitas merupakan ukuran suatu kestabilan dan konsistensi responden dalam menjawab hal yang berkaitan dengan kontruk-kontruk pertanyaan yang merupakan dimensi suatu variabel dan disusun dalam suatu bentuk kuesioner.

(Sugiyono, 2015:156) Uji normalitas kolmogorov-smirnov digunakan untuk menguji hipotesis komparatif dua sampel independen bila datanya berbentuk ordinal yang telah tersusun pada tabel distribusi frekuensi kumulatif dengan menggunakan kelas-kelas interval.

(Ghozali, 2018: 108). Uji multikolinearitas bertujuan untuk menguji apakah suatu model regresi terdapat korelasi antar variabel bebas 
(independen). Model regresi yang baik seharusnya tidak terjadi korelasi antar variabel independen. Pengujian multikolinearitas dilihat dari besaran VIF (Variance Inflation Factor) dan Tolerance. Tolerance mengukur variabel independen yang terpilih yang tidak dijelaskan oleh variabel independen lainnya. Jadi nilai tolerance yang rendah sama dengan nilai VIF tinggi (karena VIF = 1/tolerance). Nilai cutoff yang umum dipakai untuk menunjukkan adanya multikolonieritas adalah nilai Tolerance $\leq 0.10$ atau sama dengan nilai $\mathrm{VIF} \geq 10$.

(Ghozali, 2018: 137). Uji heteroskedastisitas bertujuan menguji apakah dalam model regresi terjadi ketidaksamaan variance dari residual satu pengamatan ke pengamatan yang lain. Jika variance dari residual satu pengamatan ke pengamatan yang lain tetap, maka disebut homoskedastisitas dan jika berbeda disebut heteroskedastisitas. Model regresi yang baik adalah homoskedastisitas.

(Ghozali, 2018: 97). Koefisien determinasi (Square $\mathrm{R}^{2}$ ) pada intinya mengukur seberapa jauh kemampuan model dalam menerangkan variasi variabel dependen. Nilai koefisien determinasi adalah antara nol dan 1 atau $(0<\mathrm{x}<1)$. Nilai square $\mathrm{R}^{2}$ yang kecil berarti kemampuan variabel-

\section{HASIL DAN PEMBAHASAN}

\subsection{Hasil Uji Validitas}

Uji ini digunakan untuk mengetahui butir pernyataan dalam kuesioner digunakan untuk mengukur keadaan variabel independen dalam menjelaskan variabel-variabel dependen amat terbatas.

Ghozali, (2018: 97). Nilai yang mendekati 1 berarti variabel-variabel independen memberikan hampir semua informasi yang dibutuhkan untuk memprediksi variabel dependen. Secara umum, koefisien determinasi untuk data silang (cross section) relatif rendah karena adanya variasi yang besar antara masingmasing pengamatan, sedangkan untuk data runtun waktu (time series) biasanya memiliki nilai koefisien determinasi yang tinggi..

Uji statistik $t$ menunjukkan seberapa jauh pengaruh satu variabel penjelas atau independen secara individual dalam menerangkan variasi variabel dependen (Ghozali, 2018). Jika nilai statistik $t$ hitung lebih tinggi dibandingkan $\mathrm{t}$ tabel, maka Ho ditolak atau $\mathrm{Ha}$ diterima. Hal ini menyatakan bahwa suatu variabel independen secara individual mempengaruhi variabel dependen.

(Ghozali, 2018: 98). Uji statistik F menunjukkan apakah semua variabel independen atau bebas yang dimasukkan dalam model mempunyai pengaruh secara bersama-sama terhadap variabel dependen atau terikat.

responden atau sebuah pengujian untuk membuktikan valid atau tidak valid pernyataan kuesioner dapat 
dilakukan dengan angka koefisien korelasi product moment person dengan signifikansi sebesar 0,05 .

Tabel 1 Hasil Uji Validitas Kualitas Pelayanan

\begin{tabular}{|c|c|c|c|}
\hline No & R hitung & R tabel & Keterangan \\
\hline $\mathrm{X} 1.1$ & 0,829 & 0,3610 & Valid \\
\hline $\mathrm{X} 1.2$ & 0,943 & 0,3610 & Valid \\
\hline $\mathrm{X} 1.3$ & 0,943 & 0,3610 & Valid \\
\hline $\mathrm{X} 1.4$ & 0,549 & 0,3610 & Valid \\
\hline
\end{tabular}

(Sumber: Data Penelitian, 2020

Tabel 2 Hasil Uji Validitas Kepuasan Konsumen

\begin{tabular}{|c|c|c|c|}
\hline No & R hitung & R tabel & Keterangan \\
\hline X2.1 & 0,888 & 0,3610 & Valid \\
\hline X2.2 & 0.907 & 0,3610 & Valid \\
\hline X2.3 & 0.889 & 0,3610 & Valid \\
\hline
\end{tabular}

(Sumber: Data Penelitian, 2020)

Tabel 3 Hasil Uji Validitas Loyalitas Pelanggan

\begin{tabular}{|c|c|c|c|}
\hline No & R hitung & R tabel & Keterangan \\
\hline Y1.1 & 0,972 & 0,3610 & Valid \\
\hline Y1.2 & 0.972 & 0,3610 & Valid \\
\hline Y1.3 & 0.917 & 0,3610 & Valid \\
\hline
\end{tabular}

(Sumber: Data Penelitian, 2020)

Berdasarkan tabel diatas dapat diuraikan:

1. Tabel 1 yang diolah SPSS versi 25 variabel kualitas pelayanan dapat diketahui $\mathrm{R}$ hitung lebih besar dari $\mathrm{R}$ tabel maka valid semua pertanyaan variabel kualitas pelayanan.

2. Tabel 2 Tabel 1 yang diolah SPSS versi 25 variabel kepuasan konsumen dapat dikaetahui $\mathrm{R}$ hitung lebih besar dari $\mathrm{R}$ tabel maka valid semua pertanyaan variabel kepuasan konsumen.

3. Tabel 3 yang diolah SPSS versi 25 variabel loyalitas pelanggan dapat dikaetahui $\mathrm{R}$ hitung lebih besar dari $\mathrm{R}$ tabel maka valid semua pertanyaan variabel loyalitas pelanggan.

\subsection{Hasil Uji Realibilitas}


Pengujian

menggunakan reliabilitas teknik Alpha Cronbach, dimana suatu instrumen dapat dikatakan handal (reliabel) bila memiliki koefisien kehandalan atau alpha besar 0,6 atau lebih. Apabila nilai Alpha Cronbach < 0,6 makan menyatakan instrumen yang digunakan tidak reliabel. Hasil uji reliabilitas untuk masing - masing variabel diringkas pada tabel berikut:

Tabel 4 Hasil Uji Realibilitas

\begin{tabular}{|c|c|}
\hline Variabel & Composite Reliability \\
\hline Kualitas Pelayanan $\left(\mathrm{X}_{1}\right)$ & 0.850 \\
\hline Kepuasan Konsumen $\left(\mathrm{X}_{2}\right)$ & 0.871 \\
\hline Loyalitas Pelanggan $(\mathrm{Y})$ & 0.946 \\
\hline
\end{tabular}

(Sumber: Data Penelitian, 2020)

Berdasarkan tabel diatas dapat dijelaskan:

1. Citra merek $\left(X_{1}\right)$ hasil olah data SPSS versi 25 0,850>0,60 maka variabel kualitas pelayanan realiabel.

2. kepuasan konsumen $\left(\mathrm{X}_{2}\right)$ hasil olah data SPSS versi $25 \quad 0,737>0,60$ maka variabel kepuasan konsumen realiabel.
3. Loyalitas pelanggan (Y) hasil olah data SPSS versi $25 \quad 0,737>0,60$ maka variabel loyalitas pelanggan realiabel.

Uji normalitas Uji ini dilakukan untuk mengetahui data terdistribusi dengan normal atau tidaknya. Metode yang digunakan di uji ini ialah analisis grafik normalitas..

\subsection{Hasil Uji Kolmogrov-Smirnov}

Tabel 5 Hasil Uji Kolmogrov-Smirnov

\begin{tabular}{|l|l|r|}
\hline $\mathrm{N}$ & 382 \\
\hline \multirow{2}{*}{ Normal Parameters } & Mean & .0000000 \\
\cline { 2 - 3 } & Std. Deviation & 1.49164283 \\
\hline \multirow{3}{*}{ Most Extreme Differences } & Absolute & .061 \\
\cline { 2 - 3 } & Positive & .052 \\
\cline { 2 - 3 } & Negative & -.061 \\
\hline \multicolumn{2}{|l|}{ Test Statistic } & 1.185 \\
\hline \multicolumn{2}{|l|}{ Asymp. Sig. (2-tailed) } & $.121^{\mathrm{c}, \mathrm{d}}$ \\
\hline
\end{tabular}

(Sumber: Data Penelitian, 2020)

Dari tabel diatas data normalitas diketahui bahwa nilai signifikansi (Asymp.Sig 2-tailed) sebesar 0,121. Karena signifikansi lebih dari 0,05
$(0,121>0,05)$ maka nilai data dalam penelitian ini terdistribusi secara normal. 


\subsection{Hasil Uji Multikolineritas}

Gejala multikolinieritas dapat diketahui melalui suatu uji yang dapat mendeteksi dan menguji apakah persamaan yang dibentuk Dari hasil uji multikolonieritas tidak ada variabel independen yang terjadi gejala multikolinieritas, dengan menggunakan atau melihat tool uji yang disebut VIF (variance inflation factor.

yang menunjukkan bahwa tidak ada satu variabel independen yang

Tabel 6 Hasil Uji Multikolinieritas (Coefficients ${ }^{a}$ )

\begin{tabular}{|l|r|r|}
\hline \multirow{2}{*}{ Model } & \multicolumn{2}{|c|}{ Collinearity Statistics } \\
\cline { 2 - 3 } & Tolerance & \multicolumn{2}{|c|}{ VIF } \\
\hline 1 (Constant) & & \\
Kualitas_Pelayanan & .540 & 1.852 \\
Kepuasan_Konsumen & .540 & 1.852 \\
\hline
\end{tabular}

a. Dependent Variable: Loyalitas_Pelanggan

(Sumber: Data Penelitian, 2020)

memiliki nilai tolerance kurang dari 1 dan hasil variabel inflation factor (VIF) kurang dari $10(1,852<10)$ memiliki nilai lebih besar dari 10 . Maka dapat disimpulkan bahwa persamaan model tersebut tidak terjadi multikolonieritas.

\subsection{Uji Pengaruh Analisis Regresi Berganda}

Tabel 7 Hasil Koefiesien Regresi

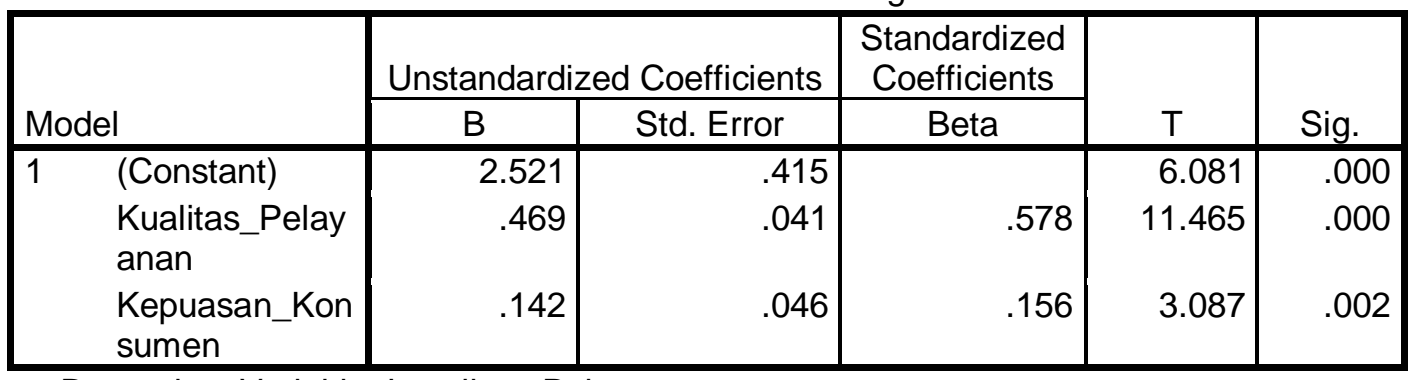

a. Dependent Variable: Loyalitas_Pelanggan

(Sumber: Data Penelitian, 2020)

Dari tabel diatas dapat dijelaskan: 
pelanggan jika tidak ada pengaruh variabel kualitas pelayanan dan kepuasan konsumen.

2. Nilai koefisien regresi variabel kualitas pelayanan 0,469 menunjukkan besarnya pengaruh variabel kualitas pelayanan terhadap loyalitas pelanggan, dimana pengaruhnya positif (searah) artinya semakin meningkat variabel kualitas pelayanan yang ditunjukkan akan menyebabkan semakin tinggi loyalitas pelanggan dan sebaliknya, jika kualitas pelayanan naik $1 \%$ atau 1 (satu), maka loyalitas pelanggan akan naik sebesar 0,469.

3. Nilai koefisien regresi variabel kepuasan konsumen diperoleh sebesar 0,142 menunjukkan besarnya pengaruh variabel kepuasan konsumen terhadap loyalitas pelanggan, dimana pengaruhnya positif (searah) artinya semakin meningkat variabel kepuasan konsumen yang ditunjukkan akan menyebabkan semakin tinggi loyalitas pelanggan dan sebaliknya, jika kepuasan konsumen naik $1 \%$ atau 1 (satu), maka loyalitas pelanggan akan naik sebesar 0,142.

\subsection{Analisis Determinasi $\left(R^{2}\right)$}

Koefisien determinasi yang digunakan adalah nilai $R$ Square karena lebih dapat dipercaya dalam mengevaluasi model regresi. Nilai $R$ Square dapat naik atau turun apabila satu variabel independen ditambahkan ke dalam model. Berbeda dengan nilai $\mathrm{R}^{2}$ yang pasti akan meningkat setiap tambahan satu variabel independen, tidak peduli apakah variabel tersebut berpengaruh secara signifikan terhadap variabel dependen.

Tabel 8 Hasil Koefisien Determinasi

\begin{tabular}{|l|c|r|r|c|}
\hline Model & $\mathrm{R}$ & $\mathrm{R}$ Square & Adjusted R Square & $\begin{array}{c}\text { Std. Error of the } \\
\text { Estimate }\end{array}$ \\
\hline 1 & $.693^{\mathrm{a}}$ & .480 & .477 & 1.496 \\
\hline & & & & \\
\hline
\end{tabular}

a. Predictors: (Constant) Kualitas_Pelayanan, Kepuasan_Konsumen

b. Dependent Variable: Loyalitas_Pelanggan

(Sumber: Data Penelitian, 2020)

Dapat dilihat bahwa nilai R2 menunjukkan nilai 0,477 besaran persentase pengaruh variabel independen secara simultan terhadap $\mathrm{Y}$ adalah dengan mengalikan $\mathrm{R} 2$ dengan $\quad 100 \%, \quad$ sehingga menghasilkan besaran $48,0 \%$. Hal ini membuktikan bahwa keputusan pembelian dapat dipengaruhi citra merek dan promosi yang memberikan 
48,0\% sedangkan $52,0 \%$ dipengaruhi oleh faktor

lain yang tidak termasuk dalam penelitian ini.

\subsection{Hasil Uji T (Parsial)}

Uji parsial sebagaimana telah dijelaskan pada metodologi penelitian adalah uji yang digunakan untuk mengetahui dan menganalisis hubungan masing-masing variabel bebas dengan variabel terikatnya.

Tabel 9 Hasil Uji T (Parsial)

\begin{tabular}{|c|c|c|c|c|c|}
\hline \multirow[b]{2}{*}{ Model } & \multicolumn{2}{|c|}{$\begin{array}{l}\text { Unstandardized } \\
\text { Coefficients }\end{array}$} & \multirow{2}{*}{$\begin{array}{c}\begin{array}{c}\text { Standardized } \\
\text { Coefficients }\end{array} \\
\text { Beta } \\
\end{array}$} & \multirow[b]{2}{*}{ T T } & \multirow[b]{2}{*}{ Sig. } \\
\hline & $\bar{B}$ & Std. Error & & & \\
\hline (Constant) & 2.521 & .415 & & 6.081 & .000 \\
\hline Kualitas_Pelayanan & .469 & .041 & .578 & 11.465 & .000 \\
\hline Kepuasan_Konsumen & .142 & .046 & .156 & 3.087 & .002 \\
\hline
\end{tabular}

a. Dependent Variable: Loyalitas_Pelanggan

(Sumber: Data Penelitian, 2020)

Hasil Uji T dapat dijelaskan bahwa:

1. Variabel kualitas pelayanan (X1) ditunjukkan dengan nilai $\mathrm{t}$ hitung sebesar 11,465 lebih besar dari $\mathrm{t}$ tabel $=1,966$ dan nilai signifikansi 0,000 lebih kecil dari 0,05 yang berarti Ho ditolak dan Ha diterima, dengan demikian maka kualtias pelayanan dinyatakan berpengaruh signifikan terhadap loyalitas pelanggan. Arah koefisien regresi positif berarti bahwa kualitas pelayanan memiliki pengaruh positif yang signifikan terhadap loyalitas pelanggan. Maka hipotesis pertama diterima.

2. Variabel kepuasan konsumen (X2) ditunjukkan dengan nilai $\mathrm{t}$ hitung sebesar 3,087 lebih besar dari $\mathrm{t}$ tabel $=1,966$ dan nilai signifikansi 0,000 lebih kecil dari 0,05 yang berarti Ho ditolak dan Ha diterima, dengan demikian maka kepuasan konsumen dinyatakan berpengaruh signifikan terhadap loyalitas pelanggan. Arah koefisien regresi positif berarti bahwa kepuasan konsumen memiliki pengaruh positif yang signifikan terhadap loyalitas pelanggan. Maka hipotesis kedua diterima.

\subsection{Hasil Uji F (Simultan)}

Uji $F$ atau uji simultan digunakan untuk mengetahui antar variabel bebas secara serentak atau bersaman berpengaruh terhadap variabel terikat. Hasil analisis data dengan menggunakan program SPSS versi 
25 menunjukkan variabel independen $\left(\mathrm{X}_{1}\right)$ yaitu Kualitas Pelayanan $\quad\left(\mathrm{X}_{2}\right), \quad$ Kepuasan Konsumen secara bersama - sama atau simultan berpengaruh terhadap variabel dependen (Y) Loyalitas Pelanggan

Tabel 10 Hasil Uji F

\begin{tabular}{|ll|r|r|r|r|r|}
\hline \multicolumn{1}{|l|}{} & \multicolumn{1}{|c|}{$\begin{array}{c}\text { Sum of } \\
\text { Model }\end{array}$} & Squares & Df & Mean Square & F & \multicolumn{1}{c|}{ Sig. } \\
\hline 1 & Regression & 782.642 & 3 & 391.321 & 174.952 & $.000^{\mathrm{b}}$ \\
& Residual & 847.724 & 379 & 2.237 & & \\
& Total & 1630.366 & 382 & & & \\
\hline
\end{tabular}

a. Dependent Variable: Loyalitas_Pelanggan

b. Predictors: (Constant), Kualitas_Pelayanan, Kepuasan_Konsumen

(Sumber: Data Penelitian, 2019)

Untuk hipotesis ketiga yang menyatakan secara simultan. Simultan terhadap loyalitas pelanggan karena nilai signifikan dari variabel kualitas pelayanan dan kepuasan konsumen sebesar 0,000 lebih kecil dari nilai $\alpha 0,05$ dan nilai F hitung sebesar 174.952 lebih besar dari nilai $F$ tabel 3,019. Maka dapat disimpulkan bahwa hipotesis ketiga diterima.

\subsection{Pembahasan}

Dengan melihat uji $\mathrm{T}$ diatas, maka berdasarkan pembahasan tabel 9 diatas diperoleh hasil variabel kualitas pelayanan $\left(\mathrm{X}_{1}\right)$ ditunjukkan dengan nilai $\mathrm{T}$ hitung sebesar 11,645 lebih besar dari t tabel $=1,966$ dan nilai signifikansi 0,000 lebih kecil dari 0,05, maka Ho ditolak dan $\mathrm{Ha}$ diterima. Maka hipotesis pertama diterima yang artinya variabel independen $\left(\mathrm{X}_{1}\right)$ berpengaruh signifikan terhadap variabel dependen (Y).
Dengan melihat uji $\mathrm{T}$ diatas, maka berdasarkan pembahasan tabel diatas diperoleh hasil variabel kepuasan konsumen $\left(\mathrm{X}_{2}\right)$ ditunjukkan dengan nilai $t$ hitung sebesar 3,087 lebih besar dari $\mathrm{t}$ tabel $=1,966$ dan nilai signifikansi 0,000 lebih kecil dari 0,05, maka Ho ditolak dan $\mathrm{Ha}$ diterima. Maka hipotesis pertama diterima yang artinya variabel independen $\left(\mathrm{X}_{2}\right) \quad$ berpengaruh signifikan terhadap variabel dependen (Y)

Hasil pengujian variabel kualitas pelayanan dan kepuasan konsumen secara simultan atau bersama-sama terhadap loyalitas pelanggan menunjukkan bahwa secara bersama variabel tingkat kualitas pelayanan dan kepuasan konsumen berpengaruh terhadap loyalitas pelanggan. Berdasarkan koefisien determinasi sebesar 0,480 menunjukkan bahwa variabel kualitas pelayanan dan kepuasan konsumen secara bersama- 
sama mempunyai pengaruh terhadap keputusan pembelian sebesar 48,0\%.

\section{SIMPULAN}

1.kualitas pelayanan berpengaruh signifikan terhadap loyalitas pelanggan PT Sumber Alfaria Trijaya Tbk.

2.kepuasan konsumen berpengaruh signifikan terhadap loyalitas pelanggan PT Sumber Alfaria Trijaya Tbk.

3.Secara Bersamaan variabel kualitas pelayanan dan kepuasan konsumen berpengaruh signifikan terhadap loyalitas pelanggan PT Sumber Alfaria Trijaya Tbk.

\section{DAFTAR PUSTAKA}

Daryanto, \& Setyobudi, I. (2014).

Konsumen dan pelayanan prima.

Yogyakarta: Gava Media.

Ghozali, I. (2018). Aplikasi Analisis

Multivariate Dengan Program

IBM SPSS 25 (9th ed.).

Semarang: UNDIP.

Kotler, P. and K. L. K. (2016).

Marketing Management, (16thEdition),. New Jersey:

Prentice Hall Published.

Putri, B. S., \& Kartika, L. (2017). Pengaruh Kualitas Pelayanan Bpjs Kesehatan Terhadap Kepuasan Pengguna Perspektif Dokter Rumah Sakit Hermina Bogor. Jurnal Riset Manajemen
Dan Bisnis (JRMB) Fakultas

Ekonomi UNIAT, 2(1), 1-12.

https://doi.org/10.36226/jrmb.v2 i1.24

Sangaji, E. M. dan S. (2013).

Perilaku Konsumen.

Yogyakarta.

Sugiyono. (2012). Metode Penelitian Kuantitati, Kualitatif dan $R \& D$. Bandung: Alfabeta.

Sugiyono. (2015). Statistika Untuk Penelitian. Bandung: Alfabeta.

Sujarweni, W. (2014). Metode

Penelitian. Yogyakarta: Pustaka Baru Press.

Tjiptono, F. dan G. C. (2012).

Pemasaran Strategi Edisi 2.

Yogyakarta: Andi. 